\title{
Hereditary Haemorrhagic Telangiectasia: A rare cause of Hepatic Encephalopathy
}

\author{
David Joughin ${ }^{1 *}$ and Peter McCanny ${ }^{2}$ \\ ${ }^{1}$ Advanced Trainee in Intensive Care Medicine, Liverpool Hospital, Australia \\ ${ }^{2}$ Consultant in Intensive Care Medicine, Liverpool Hospital, Australia
}

Submission: January 14, 2020; Published: January 30, 2020

*Corresponding author: Joughin D, Advanced Trainee in Intensive Care Medicine, Liverpool Hospital, Sydney, Australia

Abstract

Background: Hereditary haemorrhagic telangiectasia (HHT) is an autosomal dominant disorder affecting 1 in 5000-8000 individuals. It is characterised by mucocutaneous telangiectases and vascular arteriovenous malformations (AVMs). Hepatic involvement in HHT has been estimated as being as high as $67-78 \%$ but is typically asymptomatic.

Case summary: This case describes the rare complication of hepatic encephalopathy in a patient with HHT and asymptomatic, undiagnosed hepatic AVMs and the patient's management.

Conclusion: Whilst hepatic encephalopathy is a rare complication of HHT, its early and accurate diagnosis is vital in the management of patients with HHT and a decreased GCS.

Keywords: Hereditary haemorrhagic telangiectasia; Hepatic encephalopathy; Arteriovenous malformation; Decreased GCS; Coma; Magnetic resonance imaging

Abbreviations: HHT: Hereditary Haemorrhagic Telangiectasia; AVM: Arteriovenous Malformation; TGF: Transforming Growth Factor; GCS: Glasgow Coma Score; MCV: Mean Corpuscular Volume; MRI: Magnetic resonance imaging; DSA: Digital Subtraction Angiography; HOCF: High Output Cardiac Failure; VEGF: Vascular Endothelial Growth Factor

\section{Introduction}

Hereditary Haemorrhagic Telangiectasia (HHT) is an autosomal dominant vascular disorder that affects 1 in 50008000 individuals [1-3]. HHT is characterized by mucocutaneous telangiectases and vascular arteriovenous malformations (AVMs), which develop as a result of mutations in genes involved in the signalling pathways of the transforming growth factor (TGF) $\beta$ superfamily [1-5]. The clinical features of HHT develop with an increasing frequency with age, such that by the age of 40 , more than $90 \%$ of individuals affected by HHT will demonstrate some manifestation of the disorder $[1,4,6]$. Whilst the presentation of HHT can vary significantly amongst individuals depending upon the number and location of the vascular abnormalities, recurrent, spontaneous epistaxis is often the earliest symptom to develop [1,3-5]. Epistaxis is also the most common feature of HHT, occurring in over $90 \%$ of individuals, followed by skin and mucosal telangiectases (70-74\%), and then visceral AVMs [6]. The formation of AVMs occurs most frequently in the pulmonary, hepatic and cerebral circulations, with a smaller proportion developing in the spinal cord vasculature [1,4-6]. The diagnosis of hepatic involvement in HHT has been estimated as being as high as $67-78 \%$ in affected individuals when using CT, and whilst most ofatients remain asymptomatic, complications regularly occur from previously silent AVMs [4-8]. The more common of these complications include right-sided congestive heart failure, portal hypertension, and biliary disease, whilst hepatic encephalopathy accounts for one of the rarer causes of complications with a reported incidence of 2.5-19.4 per 100,000 [4,9].

\section{Case Presentation}

A 75-year-old Caucasian lady with a background of known HHT presented to the Emergency Department with an acute decrease in conscious level with a Glasgow Coma Score (GCS) reported as 12. Collateral history revealed an acute onset confusion, with the patient saying inappropriate words, and a left sided facial droop. On further questioning, the patient had been complaining of a 4-month history of intermittent confusion following a documented transient ischaemic attack. She had a past medical history of hypothyroidism, paroxysmal 
atrial fibrillation, mitral valve prolapses and had undergone a lung resection for haemoptysis several years previously. Regular medications included Thyroxine, Frusemide, Verapamil (extended release preparation), Digoxin, Simvastatin, Rabeprazole, Oral potassium and vitamin D supplementation. On examination the patient was opening eyes to voice and making incomprehensible sounds with no focal neurological deficit or lateralising signs. There were no other positive findings on a full examination of all systems. She was initially investigated according to local stroke protocol, undergoing urgent CT brain, along with CT angiography (aortic arch to Circle of Willis) and perfusion imaging. These did not show any evidence of an acute intracranial event. Initial laboratory tests revealed a Haemoglobin of 96g/L (120-150g/ L) with a Mean Corpuscular Volume (MCV) of $102.0 \mathrm{fL}$ (80$100 \mathrm{fL})$, and a White Cell Count of $3.5 \times 10^{9} / \mathrm{L}\left(4-10 \times 10^{9} / \mathrm{L}\right)$. Liver function tests demonstrated a Gamma GT 53U/L (<35U/L), an ALP $95 \mathrm{U} / \mathrm{L}$ (30-110U/L), ALT $20 \mathrm{U} / \mathrm{L}$ (5-55 U/L), AST 29 U/L (5-55 U/L), and a Protein 58g/L (60-80g/L). Whilst in the Emergency Department the patient's conscious level dropped further to a GCS of 8, mandating intubation for airway protection. She was then transferred to the Intensive Care Unit (ICU) for ongoing investigation and management. Further diagnostic workup included urinary toxicology screen which was negative for opioids, barbiturates, benzodiazepines, cocaine and its metabolites, cannabinoids, paracetamol and salicylates. A lumbar puncture was also performed, revealing a Red Cell Count of 6120 x $10^{6} / \mathrm{L}$, White Cell Count of 9 x $10^{6} / \mathrm{L}$, protein $0.24 \mathrm{~g} / \mathrm{L}(0.15-$ $0.45 \mathrm{~g} / \mathrm{L})$, glucose $4.3 \mathrm{mmol} / \mathrm{L}(2.5-4.5 \mathrm{mmol} / \mathrm{L})$ and a normal opening pressure. Subsequent magnetic resonance imaging (MRI) with contrast brain did not reveal evidence of acute infarction, but demonstrated features of previous right frontal and right cerebellar hemisphere infarctions and chronic microvascular ischemia. Further blood tests revealed a Free T4 level of $12.9 \mathrm{pmol} / \mathrm{L}$ (12.0-22.0pmol/L) and Thyroid Stimulating Hormone of $5.74 \mathrm{mIU} / \mathrm{L} \quad(0.27-4.20 \mathrm{mIU} / \mathrm{L})$, a cortisol of $1026 \mathrm{nmol} / \mathrm{L}$ (170-500nmol/L), and an Ammonia of $136 \mu \mathrm{mol} / \mathrm{L}(<60 \mu \mathrm{mol} / \mathrm{L})$. In view of this Ammonia level, the patient was commenced on regular lactulose, and within 24 hours had recovered their GCS to 15 on day 2 and was then successfully extubated on day 3 . The patient subsequently underwent a CT Triple Phase Abdomen that demonstrated multiple hepatic arteriovenous and arterioportal vascular malformations with signs of pulmonary hypertension. The two largest AVMs were in sections 2 and 6 of the liver measuring $18 \times 60 \times 20 \mathrm{~mm}$ and $20 \times 50 \times 60 \mathrm{~mm}$ respectively, both of which demonstrated communications between hepatic arteries, portal veins and hepatic veins. Note was also made of biliary dilatation, inferior vena cava dilatation, pancreatic AVMs, mild cardiomegaly and a right lower lobe pulmonary AVM. (Figure 1) A decision was made to embolise the largest of the hepatic AVMs via Digital Subtraction Angiography (DSA).The DSA demonstrated a large left gastric artery from which the left hepatic artery arose. Extensive abnormal vessels were also noted within the liver with quick shunting of blood into both hepatic and portal veins. Stasis of flow in the left hepatic artery was achieved via microcatheter coil embolization following multiple coil deployments. The patient tolerated the procedure well, demonstrating continued improvement, and was subsequently discharged home on longterm daily lactulose in addition to her usual medications. (a)

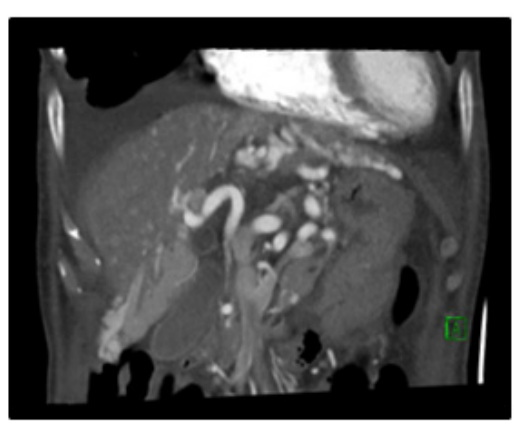

(b)

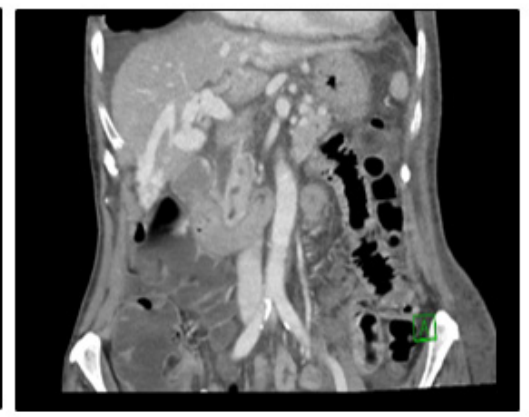

Figure 1: (a) Arterial Phase Coronal CT demonstrating Arteriovenous Malformation in left and right lobes of the liver.

(b) Porto venous Phase Coronal CT demonstrating dilated hepatic veins.

\section{Discussion}

A decreased level of consciousness is a common cause for presentation to hospital and accounts for up to $20 \%$ of medical admissions to ICU. Amongst the general population, the number of differentials for a decreased level of consciousness is extensive and can occur as a result of pathology in any organ system. It is important that these differential diagnoses are also considered and excluded in patients with HHT presenting with a reduced level of consciousness, as guided by clinical features and in conjunction 
with laboratory and radiological investigations. However, the high incidence of AVMs in this subset of patients increases the likelihood that the decrease in conscious level may have arisen as a result of a complication from a cerebral, pulmonary or hepatic AVM when compared to the general population $[4,10]$. The development of hepatic AVMs is common amongst patients with HHT [4]. However, fewer than $25 \%$ of these patients become symptomatic and those that do typically present with High Output Cardiac Failure (HOCF), pulmonary hypertension or biliary disease, either in isolation or concurrently $[4,10]$. A far less common presentation is with a decreased level of consciousness resulting from hepatic encephalopathy, as occurred in this case [9]. It is far more likely that an altered level of consciousness would result from the sequelae of a cerebral AVM, such as a haemorrhage, than a hepatic AVM, and it is important to exclude these as a cause in an expeditious fashion, with the appropriate investigations and brain imaging ${ }^{[4,9,10]}$. In individuals that subsequently have unremarkable brain imaging, the relatively high incidence of asymptomatic hepatic AVMs should confer a high index of suspicion for a portosystemic shunt. The diagnosis of hepatic encephalopathy secondary to a portosystemic shunt from clinical findings and routine biochemical investigations alone can be difficult. The most common biochemical abnormality in patients with HHT and hepatic AVMs is an anicteric cholestasis which is seen as a raised Gamma GT and ALP $[1,3,10]$. However, this is not universally true and there may be no, or only slight abnormalities in routine liver function tests, as apparent in this case [3,11,12]. In these circumstances an elevated serum ammonia level will aid in the diagnosis of hepatic encephalopathy, although it is important to be mindful of the fact that up to $10 \%$ of patients with severe hepatic encephalopathy have normal serum ammonia [10]. It is also important that the diagnosis of hepatic encephalopathy is not made on the basis of a raised serum ammonia alone, but is made in conjunction with normal brain imaging and a clinical picture consistent with an encephalopathy without focal neurology, as serum ammonia levels may be elevated in up to $69 \%$ of patients without hepatic encephalitis $[10,12,13]$.

Intensive medical therapy is the first line treatment for patients with HHT and symptomatic AVMs $[4,10,14]$. For patients with hepatic encephalopathy, this includes the early initiation of osmotic laxative therapy and an appropriate escalation of treatment if this fails. If hepatic encephalopathy is the first presentation of hepatic involvement in patients with HHT then subsequent investigation with Ultrasound (US) Doppler or CT Abdomen is warranted to further characterise the AVMs $[4,10,14]$. Transthoracic Echocardiography should also be performed to assess for HOCF and presence, or severity of pulmonary hypertension. If features of HOCF or pulmonary hypertension present then these should be managed accordingly $[4,14]$. Bevacizumab, a Vascular Endothelial Growth Factor (VEGF) Inhibitor, has shown clinical benefit in patients with HOCF, life threatening or refractory epistaxis and gastrointestinal bleeding. However, its use is not without adverse effects which include, but are not limited to, poor wound healing [15-17]. This is important as it could potentially have a negative impact on patients who may go on to require liver transplantation and therefore careful patient selection is required $[14,16]$. Liver transplantation is the only definitive treatment for patients with HHT and symptomatic hepatic AVMs that have failed to respond to medical therapy [14-16]. Indications for liver transplantation include intractable HOCF, complicated pulmonary hypertension and biliary necrosis [14,15] Hepatic artery embolization or ligation is a less invasive and viable alternative to liver transplantation, although complications occur in up to $42 \%$ of cases and recurrence of AVMs has been documented [4,14,18,19]. The early and accurate diagnosis of hepatic encephalopathy is an important part of the management of patients with HHT and a decreased GCS. As a result, we recommend that for patients who present with an altered level of consciousness of unclear aetiology, that measurement of serum ammonia level should be performed to diagnose or exclude hepatic encephalopathy, regardless of whether there are normal liver function tests. Early referral to the appropriate gastroenterology or hepatology teams, as well as subsequent hepatic imaging via US Doppler or CT, are also fundamental in the acute management of hepatic encephalopathy in patients with HHT.

\section{Conflict of Interests}

The Author(s) declare(s) that there is no conflict of interest

\section{Consent}

This report is published with the written consent of the patient

\section{References}

1. Govani FS, Shovlin CL (2009) Hereditary haemorrhagic telangiectasia: a clinical and scientific review. Eur J Hum Genet 17(7): 860-871.

2. Faughnan ME, Palda VA, Garcia-Tsao G, Geisthoff UW, McDonald J, Proctor DD, et al. (2011) International guidelines for the diagnosis and management of hereditary haemorrhagic telangiectasia. J Med Genet 48(2): 73-87

3. Shovlin CL, Guttmacher AE, Buscarini E, Faughnan ME, Hyland RH, Westermann CJ, et al. (2000) Diagnostic criteria for hereditary hemorrhagic telangiectasia (Rendu-Osler-Weber syndrome). Am J Med Genet 91: 66-67.

4. Larson A (2003) Liver disease in hereditary hemorrhagic telangiectasia. J Clin Gastroenterol 36:149-158

5. Buscarini E, Plauchu H, Garcia Tsao G, White RI Jr, Sabbà C, Miller F, et al. (2006) Liver involvement in hereditary hemorrhagic telangiectasia: consensus recommendations. Liver Int 26(9): 1040-1046

6. Begbie ME, Wallace GM, Shovlin CL (2003) Hereditary haemorrhagic telangiectasia (Osler-Weber-Rendu syndrome): a view from the 21st century. Postgrad Med J 79(927): 18-24

7. Wu JS, Saluja S, Garcia-Tsao G, Chong A, Henderson KJ, et al. (2006) Liver Involvement in Hereditary Hemorrhagic Telangiectasia: CT and Clinical Findings Do Not Correlate in Symptomatic Patients. AJR Am J Roentgenol 187(4): 399-405. 
8. Cottin V, Plauchu H, Bayle JY, Barthelet M, Revel D, et al. (2004) Pulmonary arteriovenous malformations in patients with hereditary hemorrhagic telangiectasia. Am J Respir Crit Care Med 169(9): 994 1000 .

9. Ha J, Son BK (2015) Rare Cause of Hepatic Encephalopathy: Hereditary Hemorrhagic Telangiectasia. J Neuroinfect Dis 6: 102.

10. Garcia-Tsao G (2007) Liver involvement in hereditary hemorrhagic telangiectasia (HHT). J Hepatol 46(3): 499-507.

11. Haitjema T, Westermann CJ, Overtoom TT, Timmer R, Disch F, et al (1996) Hereditary hemorrhagic telangiectasia (Osler-Weber-Rendu disease): new insights in pathogenesis, complications, and treatment. Arch Intern Med 156(7): 714-719.

12. Ong JP, Aggarwal A, Krieger D, Easley KA, Karafa MT, et al. (2003) Correlation between ammonia levels and the severity of hepatic encephalopathy. Am J Med 114(3): 188-193

13. Watanabe A (2000) Portal-systemic encephalopathy in non-cirrhotic patients: classification of clinical types, diagnosis and treatment. Gastroenterol Hepatol 15(9): 969-979.

14. (2016) EASL Clinical Practice Guidelines: Vascular diseases of the liver. J Hepatol 64(1): 179-202.
15. Dupuis-Girod S, Ginon I, Saurin JC, Marion D, Guillot E, et al. (2012) Bevacizumab in patients with hereditary hemorrhagic telangiectasia and severe hepatic vascular malformations and high cardiac output. JAMA 2012; 307(9): 948-955.

16. Guilhem A, Fargeton AE, Simon AC, Duffau P, Harle JR, et al. (2017) Intra-venous bevacizumab in hereditary hemorrhagic telangiectasia (HHT): A retrospective study of 46 patients. PLoS One 12(11): e0188943.

17. Iyer VN, Apala DR, Pannu BS, Kotecha A, Brinjikji W, et al. (2018) Intravenous Bevacizumab for Refractory Hereditary Hemorrhagic Telangiectasia-Related Epistaxis and Gastrointestinal Bleeding. Mayo Clin Proc 93(2): 155-166.

18. Liu ZC, Lu XF, Yang H, Liu HD, Song X, et al. (2016) Clinical outcomes of patients with severe hepatic hereditary hemorrhagic telangiectasia after banding of the hepatic artery and banding/ligation of branches of the hepatic artery. Eur J Vasc Endovasc Surg 51(4): 594-601

19. Caselitz M, Wagner S, Chavan A, Gebel M, Bleck JS, et al. (1998) Clinical outcome of transfemoral embolisation in patients with arteriovenous malformations of the liver in hereditary haemorrhagic telangiectasia (Weber rendu-Osler disease). Gut 42(1): 123-126.

Your next submission with Juniper Publishers will reach you the below assets

- Quality Editorial service

- Swift Peer Review

- Reprints availability

- E-prints Service

- Manuscript Podcast for convenient understanding

- Global attainment for your research

- Manuscript accessibility in different formats

( Pdf, E-pub, Full Text, Audio)

- Unceasing customer service

Track the below URL for one-step submission https://juniperpublishers.com/online-submission.php 